\title{
SIGUIENDO LOS PASOS DE LAS SEMILLAS: UTILIZACIÓN DEL SISTEMA DE INFORMACIÓN GEOGRÁFICA PARA GEORREFERENCIAR HUERTAS VINCULADAS A LA AGENCIA INTA RÍO CUARTO
}

\author{
Toledo $\mathrm{M}^{1}$, Tamiozzo $\mathrm{L}^{1}$, Vier $\mathrm{F}^{2}$, Canale $\mathrm{A}^{1}$, Heguiabehere $\mathrm{A}^{2}$, \\ Salas $\mathrm{B}^{1}$, Boldrini $\mathrm{C}^{1}$, Barbeito, $\mathrm{A}^{2}$
}

\author{
${ }^{1}$ INTA AER Río Cuarto. Mitre 656 (5800) Río Cuarto. Córdoba. Argentina. \\ ${ }^{2}$ Facultad de Agronomía y Veterinaria UNRC. \\ * Correspondencia: Toledo M., E-mail: toledo.marcelo@inta.gob.ar
}

FOLLOWING THE STEPS OF THE SEEDS: USE OF THE GEOGRAPHICAL INFORMATION SYSTEM TO GEOREFERENCE VEGETABLE GARDENS LINKED TO THE INTA RÍO CUARTO AGENCY

SUMMARY

\begin{abstract}
The Pro-Huerta program delivers the autumn-winter and spring-summer seasonal seed kits free of charge to all INTA agencies. Each seed kit removed from the agency by the beneficiary, is registered in a form with the information of the address where the vegetable garden will be and a contact number. Using the data and a geographic information system (GIS), it was possible to georeference the potential vegetable gardens in the city of Río Cuarto, becoming a tool for intervention and territorial accompaniment of the extension agency in order to plan the survey and monitoring of activities productive of them.
\end{abstract}

Palabras clave: semillas, huertas, georreferenciar.

Keywords: seed, vegetable garden, georeference.

El programa Pro-Huerta entrega los kits de semillas de temporada otoño-invierno y primavera-verano en forma gratuita en todas las agencias del INTA; el mismo se dirige a familias en situación de vulnerabilidad, para que puedan acceder a la autoproducción de sus alimentos. Hoy alcanza a más de tres millones de personas en todo el país ${ }^{1}$, articulando con huerteros, promotores voluntarios, municipalidades, instituciones educativas, organizaciones no gubernamentales, centros de jubilados, vecinales, parroquias, hogares y copas de leche. Cada kit de semillas retirado de la agencia por el beneficiario, es registrado en una planilla con sus datos, el domicilio donde estará la huerta y un número de contacto. De esta manera cada kit se transforma en una potencial huerta. Desde la Agencia de Extensión Rural (AER) del INTA Río Cuarto se viene trabajando para identificar las huertas que se establecen en la ciudad y el monitoreo de las mismas. El objetivo general: 
georreferenciar las huertas vinculadas a la AER de INTA Río Cuarto, temporada primavera-verano 2017 usando un sistema de información geográfica (SIG). Los objetivos específicos: visualizar los puntos de destinos de las semillas en un territorio determinado y mostrar la distribución de los puntos en barrios y asentamientos urbanos $^{2}$. La actividad se llevó adelante con dos estudiantes, que a partir de un convenio de articulación con la Universidad Nacional de Río Cuarto realizan sus pasantías y práctica profesional en la AER, para la carga de datos y sistematización de la información en continua colaboración con los agentes del INTA. Se digitalizaron en planillas Excel los datos registrados en la entrega de semillas y a posterior, se organizó y cartografió la información mediante de la utilización de Google Earth Pro y QGIS 2.18.12. La elección de trabajar con el software Google Earth Pro y QGIS 2.18 se basó en que son de acceso gratuito las imágenes correspondiente a la ciudad de Río Cuarto y la región de interés; cuentan con actualización de la información; permiten la selección de la escala según las necesidades del trabajo y ambos son programas conocidos y utilizados por la población en general, a nivel local, regional, nacional y mundial; permiten obtener nuevos datos mediante las funciones de geoprocesos y combinaciones de capas $^{3}$. Tras la digitalización de los objetos y límites con puntos, líneas y polígonos, y las actividades de geoprocesos se sintetizó la información mediante la representación cartográfica de los mapas. Los mismos muestran: 1966 huertas familiares distribuidas en 14 barrios de la ciudad (ver Figura 1), 9 asentamientos con 52 huertas (ver figura 2 y 3) y 22 huertas institucionales distribuidas de la siguiente manera: 2 escolares, 3 en centros de jubilados, 5 en parroquias, 2 en vecinales, 7 en diferentes ONG's y 3 en hogares o asilos (ver Figura 4). La información obtenida permite conocer la localización de las potenciales huertas en la ciudad y se convierte en una herramienta de intervención y acompañamiento territorial de la agencia de extensión para poder planificar el relevamiento y el monitoreo de las actividades productivas de las mismas.

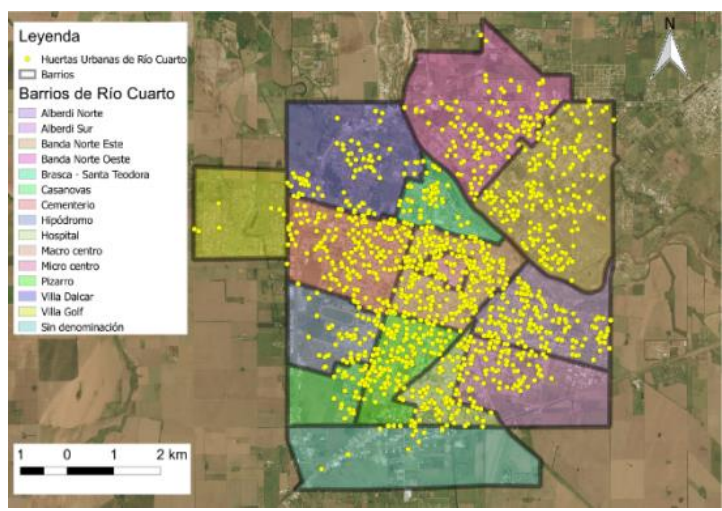

Figura 1. Distribución de las potenciales huertas en la ciudad de Río Cuarto.

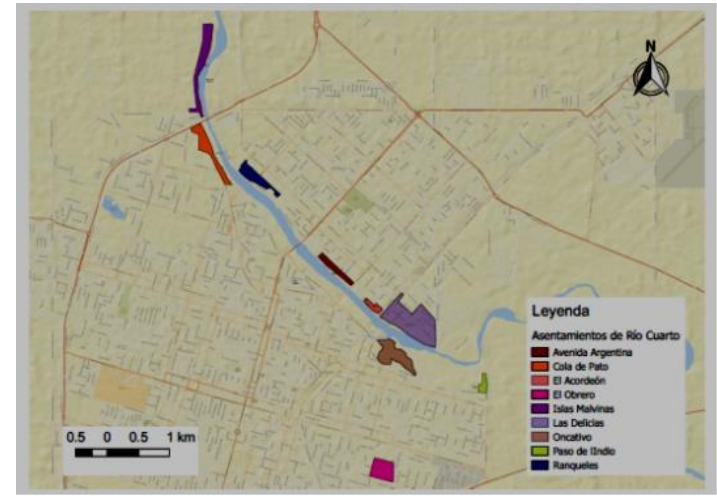

Figura 2. Asentamientos urbanos en la ciudad de Río Cuarto. Año 2017.

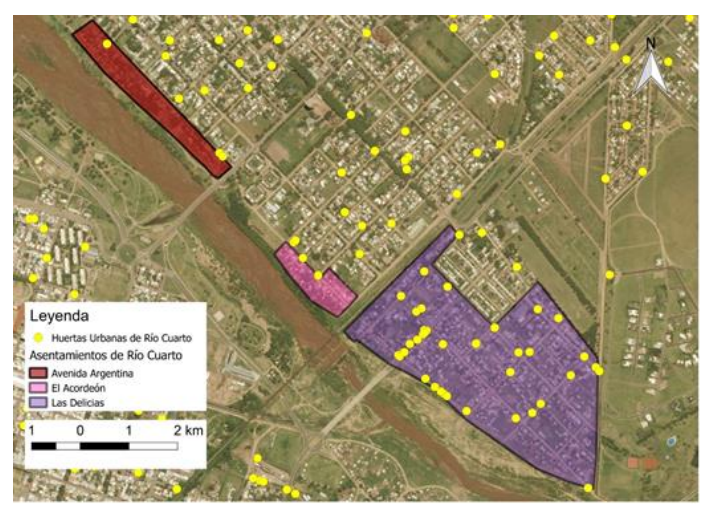

Figura 3. Distribución de las huertas en algunos asentamientos urbanos de la ciudad de Río Cuarto.

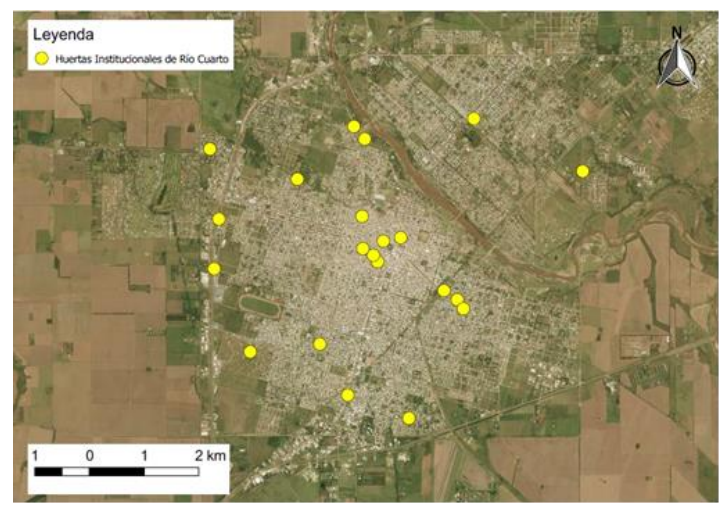

Figura 4. Distribución de las huertas institucionales en la ciudad de Río Cuarto.

\section{Bibliografía}

1http://www.desarrollosocial.gob.ar/prohuerta/149/?hc location=ufi. Consultado el 18/08/2019

2http://www.riocuarto.gov.ar/maparioiv/tilecache/densi dadpoblacional/ Consultado el 21/08/2019

3https://docs.qgis.org/2.18/en/docs/user manual/pream ble/whats new.html. QGIS User Guide. Consultado $09 / 09 / 2019$ 